\title{
LA AUDITORÍA CON ENFOQUE AMBIENTAL EN EL DERECHO PÚBLICO CUBANO
}

\section{The Auditing with Environmental Focus in the Public Right Cuban}

\author{
ALCIDES FRANCISCO ANTÚNEZ-SÁNCHEZ ${ }^{1}$ \\ ${ }^{1}$ Máster en Asesoría Jurídica. Profesor Auxiliar Derecho Ambiental y Mercantil. \\ Facultad de Ciencias Económicas y Sociales. Universidad de Granma. República de Cuba.
}

\section{E-mail: aantunez@udg.co.cu}

antunez63@nauta.cu

Recibido: 17 de Septiembre de 2015

Aceptado: 29 de Octubre de 2015

\section{Resumen}

La regulación jurídica de la auditoría ambiental en las formas de gestión, apunta como un paso en el avance por el órgano supremo de control. Para ello, se realiza un análisis epistemológico de su íter histórico, teórico, legislativo del desarrollo y evolución del control ambiental a través de la auditoría pública; para formular presupuestos jurídicos y actualizar las disposiciones jurídicas en relación con las insuficiencias que posee en el ordenamiento jurídico. Necesaria para construir empresas amigables con el ambiente en la actualización del modelo económico cubano. A tales efectos, para desarrollar este análisis se utilizaron los métodos teóricos de investigación como el exegético-jurídico, el históricológico, inducción-deducción y el de análisis-síntesis.

Palabras claves: auditoría ambiental, formas de gestión, desarrollo sostenible, empresa amigable con el ambiente.

\section{Abstract}

The juridical regulation of the environmental auditing in the forms of management, points like a step in the advance for the supreme organ of control. For it, one of his historical iter's epistemological analysis is accomplished, theoretic, legislative of development and evolution of the environmental control through the public audit; In order to formulate juridical budgets and to updating the juridical dispositions relating to the insufficiencies that possess in the juridical organizing. Necessary to construct friendly companies with the environment in bring up to date of the economic model Cuban. To develop this analysis had used the theoric methods of research like the exegetic-juridical, the logic hitoric, induction-deducticon and the synthesis analysis.

Key words: environmental auditing, forms of step, sustainable development, friendly company with the environment. 


\section{OJEADA HISTÓRICA A LA AUDITORÍA AMBIENTAL EN EL DERECHO PÚBLICO PATRIO}

Los saberes contables e históricos marcan los albores del ejercicio de la auditoría como una función pública, la que en su generalidad no era conocida del todo a consecuencia de ser Cuba una colonia española. El período del siglo XVII hasta el XVIII, evidencia que el control a las finanzas públicas estuvo constituido por los órganos de la Intendencia de Hacienda y el Tribunal de Cuentas. Es así, que ya para el siglo XIX, con el Decreto No. 78, como Ley del Poder Ejecutivo, se regularon las funciones de fiscalización, ejercitadas por el Interventor General de la República. Acciones jurídicas que tuvieron su sustento en la Constitución de 1940, al regular la fiscalización a los bienes públicos por el Ministerio de Hacienda, institución creada por la Ley Orgánica del Poder Ejecutivo; se evidenció además la creación del Tribunal de Cuentas, el que fiscalizó el patrimonio, los ingresos, los gastos del Estado y a los organismos autónomos en esta época.

Es verdad, que los cambios acontecidos a nivel mundial en los objetivos de la auditoría, la que solo se dedicaba en sus orígenes a la detección de fraudes, a la revisión de los sistemas y a la obtención de las evidencias; se ha extendido al control de los recursos naturales al tomarse conciencia mundial de los altos índices de contaminación generados por la industria. Factores que propiciaron se reconocieran otros tipos de auditorías como las de gestión y las operativas, la de eficiencia y la de economía, respondieron a las necesidades sociales, vinculadas al control administrativo ambiental, como el instrumento protector del ambiente entre los mecanismos utilizados por la Administración Pública, integrada a la realización de las revisiones clásicas que se efectuaban en otras ramas y sectores de la industria, al ser la de mayor incidencia en la contaminación.

Como una realidad, al triunfar la Revolución, el gobierno dota al país de un mecanismo más eficaz para salvaguardar los intereses del pueblo, es creado para ello en 1959 el Ministerio de Recuperación de Bienes Malversados para ejecutar esta función pública, a raíz de los cambios y las modificaciones en la estructura económica ejecutados con la sustitución del Tribunal de Cuentas en 1960.

Es por ello, que en 1961, se constituye el Ministerio de Hacienda con la Ley No. 943, al mismo se le concedieron funciones para la comprobación de los gastos del Estado con la Dirección de Comprobación, encargada de realizar la fiscalización. Al finalizar 1965, este órgano es disuelto, pasando estas funciones al Banco Nacional de Cuba, con la misma Dirección de Comprobación y con la función de ejercitar la auditoría estatal. Con posterioridad fue creado el Ministerio de Industrias y con ello la decisión de conformarse las primeras Unidades de Auditoría Interna en el país.

Para 1976, con la institucionalización sustentada en la Ley No. 1323, se crea el Comité Estatal de Finanzas, con ello se reanuda la Dirección de Comprobación y con esta la práctica de la auditoría estatal por parte del Estado. Sustentada a partir de lo establecido en el texto constitucional, artículo 10 y cito:

(..."todos los órganos del Estado, sus dirigentes, funcionarios y empleados, actúan dentro de los límites de sus respectivas competencias y tienen la obligación de observar estrictamente la legalidad socialista y velar por su respeto en la vida de toda la sociedad"...)

Función pública concebida por el Derecho Administrativo dentro de las formas de actividad administrativa como actividad policía- en la nación cubana, toda vez que la mayor representatividad de empresas están en la formas de gestión estatal, se aprecia regulada a partir del texto constitucional y en el ordenamiento jurídico sustantivo en los Decretos Leyes No. 67 de 1983 y el 147 de 1994, modificados al continuarse reformando los organismos de la Administración Pública.

La década de los 80, mostró sucesos internacionales y nacionales con repercusión en la auditoría estatal, vinculados al desplome del campo socialista y con la Unión Soviética como el principal socio comercial, elementos que obligaron al Estado a buscar otros horizontes en la actividad económica y en las relaciones comerciales, a través de asociaciones económicas con la inversión extranjera en los bloques económicos regionales que hoy aparecen en América Latina como el MERCOSUR, UNASUR, la CELAC y el ALBA.

En la década de los 90 cesan las funciones del Comité Estatal de Finanzas y Precios, trasladadas al Ministerio de Finanzas y Precios y con ello se creó la Oficina Nacional de Auditoría (ONA). Esta tuvo su sustento legal en el Decreto Ley No. 159 de 1995, como Ley de la Auditoría en la nación. Practicada a las formas de gestión por la ONA y por las Sociedades Civiles, legitimadas a través del título habilitante y la autorización administrativa. Sustentadas en el Acuerdo No. 
2819 del Comité Ejecutivo del Consejo de Ministros de 1995 y en el Decreto No. 228 de 1997 para la ejecutar la potestad sancionadora al exigir la responsabilidad a través del Derecho Administrativo Sancionador. Este Ministerio, al tomar el control de la auditoría pública, dictó directivas para la confección del plan de auditorías, y se creó el Registro de Auditores de la República, el que permitió la habilitación de los profesionales para esta función pública.

Desde 1985 hasta 1993, se comprobó que fueron realizados estudios vinculados con la forma más ventajosa de implementar y fortalecer los mecanismos de control como Estado vigilante, para crear un órgano de fiscalización superior. Es así, que entre 1999 al 2000, se continuaron otros estudios para consumar la propuesta de crear un órgano soberano, sobre la experiencia alcanzada en América Latina $\mathrm{y}$ en la Unión Europea, en correspondencia con las regulaciones de las EFS -INTOSAI- para adaptarlo al país y a las nuevas concepciones mundiales. Para ello, se creó el Ministerio de Auditoría y Control (MAC), como el organismo encargado de dirigir, ejecutar y controlar la aplicación de la política del Estado y del Gobierno en las materias de la auditoría gubernamental, la fiscalización y el control gubernamental; para organizar, dirigir y controlar todo el Sistema Nacional de Auditoría Pública en el país. Es verdad, que la práctica de la auditoría pública, continuó dirigida en esencia a la revisión de los sistemas contables de las formas de gestión, prueban que sus primeras manifestaciones como instrumento de gestión ambiental no se practicó, solo existen evidencias de su ejecución en las auditorías de gestión y la de cumplimiento, las que controlaron temáticas afines a la protección ambiental. Caracterizada por ser gratuita, obligatoria y ejecutada a través de un plan con periodicidad anual.

En consecuencia, dentro del proceso de institucionalización analizado up supra, es también apreciado que la auditoría estatal y en especial la protección ambiental ha tenido un espacio superior a partir de su regulación normativa en el texto constitucional, refrendado en ulteriores leyes dictadas por el órgano con competencia en materia ambiental; el Ministerio de Ciencias, Tecnología y Medio Ambiente (CITMA) como parte del derecho sustantivo en la nación. Este ha dictado acciones protectoras dirigidas hacia el ambiente, en correspondencia a los Tratados ambientales de que es parte la nación. Constatados a partir del Capítulo I del texto constitucional: Fundamentos Políticos, Sociales y Económicos del Estado, al distinguirse cuatro ámbitos de incidencia: la protección del medio ambiente como principio constitucional rector de la política económica y social, la función pública de protección ambiental como mandato de acción para el Estado; la protección ambiental como ámbito de atribuciones y competencias y la protección de los recursos naturales y de todo el rico potencial de la naturaleza como un deber ciudadano.

En su aplicación, se instituye como un principio constitucional de actuación de los órganos estatales, toda vez que se convierte en el soporte informador del ordenamiento jurídico patrio. Donde el artículo 27, consagra la protección ambiental como función pública. Técnicamente, a la vez que se habilitaron los órganos competentes para que intervengan en la protección del medio ambiente inspirados en el desarrollo sostenible.

Se ordenó la aplicación de dicha habilitación con el objetivo de:

\footnotetext{
"hacer más racional la vida humana y asegurar la supervivencia, el bienestar y la seguridad de las generaciones actuales y futuras"
}

No obstante, aún se considera que quedan retos ambientales en la carta magna para reforzar las materias vinculadas a la protección del ambiente, el reparto de las atribuciones y de las competencias creando mecanismos más adecuados. A partir de los principios de organización y actividad de los órganos estatales establecidos en el artículo 68 y en virtud de estos se integran y desarrollan sus acciones sobre la base de la democracia socialista, en las tareas de su competencia, la obligatoriedad de las disposiciones de los órganos superiores para los inferiores, la subordinación y rendición de cuentas de estos últimos a los superiores lo que garantizará el respeto, la articulación y el control de la política ambiental.

Para ello, con la creación del CITMA se materializó toda esta política ambiental, tuvo su sustento en un número de Leyes, Decretos Leyes, Normas y Resoluciones, para garantizar la adecuada obediencia de la "Ecuación Para la Vida" al ejecutar la función inspectiva. Le permitió conocer a la Administración Pública los índices de contaminación con la aplicación de los sistemas de gestión ambiental, y el uso e implementación de las tecnologías limpias, como meta hacia la sostenibilidad ambiental (Antúnez-Sánchez 2015a) 
Los que se aprecian estar vinculados al control ambiental a través de la inspección ambiental, la Evaluación de Impacto Ambiental, afín a las políticas del desarrollo económicosocial, por la trascendencia y la relación que tienen con la auditoría ambiental, la que debería ser practicada en la mayoría de las acciones vinculadas con el medio ambiente construido. Toda vez, que estas acciones pudieran colisionar con los momentos del control tecnológico que corresponden a las fases de la auditoría ambiental, no solo a la tecnología existente sino también a las previstas a introducirse por la Administración Pública, afín a la implementación y evaluación de la Responsabilidad Social Empresarial en la ISO 26000 y a los principios que desde el Derecho Ambiental la informan cómo en su práctica como el precautorio, el de prevención, de responsabilidad, de autocontrol, quien contamina paga, sostenibilidad y el de cooperación al decir de autores como Martín-Mateo (1991), Caferrata (2010), Sanz-Larruga (2012), Antúnez-Sánchez (2015c), entre otros.

Es una realidad hoy, que con la actualización y reforma del modelo económico, la creación de la Contraloría General de la República como el órgano de control supremo, sustentada en la Ley No. 107 de 2009, le ha permitido al país insertarse en las novedosas tendencias internacionales declaradas por las EFS -INTOSAI-, como el órgano que auxiliará a la Asamblea Nacional y al Consejo de Estado en la ejecución de la más alta fiscalización sobre los órganos del Estado y del Gobierno. El país con ello, entró en una etapa superior en la actividad de control a los bienes públicos y en especial a la dimensión ambiental, a partir de que su sustento legal da una atención adecuada al hecho de que tanto los daños como la restauración ambiental acarrean costos reales a la organización implicada, al regularse la auditoría ambiental como una de los tipos para la actividad de control administrativo en su Reglamento del 2010, la que debió ser reglada en la Ley y el legislador no la previó de esta forma, válido para la Ley del Medio Ambiente donde tampoco se le reguló (Antúnez Sánchez 2015d).

No obstante, este tipo de control administrativo ambiental en el país ahora es que se ha reconocido, pero sin un programa para realizar este tipo de auditoría, donde se incluyan los elementos objetivos, subjetivos y formales en la normativa jurídica en atención a la transversalidad, a la multidisciplinariedad y la multidimensionalidad que tiene este tipo de control ambiental. (Antúnez Sánchez 2015b) Lo que a criterio de este autor, entra en contradicción a las pautas de las EFS de América Latina y el Caribe, las que en estos temas tienen avances y en otras regiones del mundo se actualizan, renuevan y evolucionan como en la Unión Europea, donde se distingue la empresa y la industria con las EMAS, se exige la responsabilidad patrimonial y se aplica la norma ISO 26000 a la formas de gestión al certificar el comercio justo como uno de los valores agregados de este tipo de control.

Por ello se considera, que esta acción de control, podrá ser aplicada al $100 \%$ a todas las formas de gestión que en este siglo XXI se fomentan en el país, pero se estima también que en este órgano de control deberá crear las condiciones de cómo se organizará y demandará, se requerirá de un diagnóstico de lo actual y lo puntual, que permita proyectar un plan de auditorías por su vínculo con otras herramientas de la gestión; que se inician desde la arista económica donde aparece la tributación ambiental como una novedad institucional, reconocida en la legislación tributaria, donde este órgano supremo juega su rol en la cuantificación del daño ambiental relacionado con el vertido ambiental que emana de las industrias.

Todo esto conllevará, a que habrá que replantearse un nuevo Derecho Ambiental en la nación cubana, que permita equilibrar los fundamentos doctrinales, la normativa ambiental y la praxis jurídico-administrativa por los actores de la Administración Pública por la multidimensionalidad que tiene la auditoría ambiental. Que permita el cambio en la forma en que el ser humano percibe su relación con el ambiente y como interactuará con él, a partir del binomio deber-derecho, por la transversalidad e interdisciplinariedad que posee la práctica del control ambiental, para su desarrollo y evolución desde la arista económica hacia la jurídica y con ello conformar la empresa amigable con el ambiente en la nación.

Es así, que esta auditoría ambiental en su regulación normativa, no establece la certificación ambiental al concluir; de uso en la doctrina consultada en la región de Iberoamérica, por los beneficios que su valor agregado trae para el comercio a los empresarios que la solicitan ante mercados ambientales exigentes que solicitan productos y servicios que obtengan la etiqueta-certificación ambiental. Por lo que se considera que este aspecto negativo deberá resolverse por el legislador nacional. Y que en el caso cubano, a consecuencia del hostigamiento político sostenido por el bloqueo económico por más de 50 años por los Estados Unidos de América se depende de la fuerza y los recursos propios, en la medida que el país sea capaz de 
integrar los procesos naturales, sociales, económicos y culturales con los del desarrollo económico aparejados al progreso del intelecto del capital humano en la actualización y la reforma del modelo económico-social, entonces podrán ser aplicadas las fórmulas I+D e Investigación + Desarrollo + Comercio en las formas de gestión (Ospina-Duque 2011).

Para ello, de implementarse la auditoría ambiental, se considera estará desnivelada, al no estar implementada la contabilidad ambiental dentro del Sistema Contable Nacional, como lo señala el PNUMA y las EFS, que permita lograr resultados al analizarse la relación costo-volumenutilidad, que permitirá controlar en que se utiliza el presupuesto financiero destinado a esta actividad y ser este otro de los valores agregados al ser certificada su contabilidad, factor que propiciará una imagen corporativa positiva al implementarse la fórmula Investigación + Desarrollo + Innovación cuyo resultante sería la Empresa Amigable con el Ambiente (Antúnez Sánchez 2015d).

En consecuencia, se considera, la protección del bien jurídico ambiental en el país parte de la firma de Convenios y Acuerdos Internacionales con las EFS -INTOSAI- en las materias de contabilidad, auditoría y medio ambiente, integrados a partir de la norma constitucional y la legislación ambiental desarrollada en el ordenamiento jurídico, coinciden estima este autor, que la omisión por parte del legislador de su no adecuada implementación puede haber sido una de las causales de la fragmentación de la normativa ambiental, necesitada de una apropiada construcción normativa a futuro, que permita evolucionar a tono con las políticas actuales en la región de lberoamérica, en temáticas como la responsabilidad ambiental en materia civil, administrativa, penal como la objetiva, la evaluación ambiental estratégica, la cobertura financiera a través del seguro ambiental y el uso de las tecnologías limpias en los sujetos económicos. Como su reconocimiento en el texto constitucional como órgano de control, al decidirse la reforma constitucional del texto mano cubano (AntúnezSánchez 2015c).

Deberá también analizarse la creación dentro de la Fiscalía de áreas especializadas en la materia ambiental, como la solución en sede judicial ambiental de los conflictos generados. En todo este contexto, las causales que han conllevado a que el país tenga acumulado todas las situaciones ambientales adversas, han sido los patrones de producción utilizados, el consumo y el uso de los recursos no han sido los más adecuados con alta incidencia en la contaminación; la degradación de los suelos; la pérdida de diversidad biológica; la carencia, disponibilidad y calidad del agua potable y la afectación de la cobertura forestal. Siendo las principales causas que inciden en la situación de la contaminación ambiental además de las señaladas son: la no aplicación de enfoques preventivos; la carencia de recursos y materiales para minimizarlos y dar tratamiento de manera no adecuada a los residuos y emisiones generados por el sector estatal vinculados con el vertido ambiental; la no adecuada operación y mantenimiento de los sistemas de gestión; la educación ambiental insuficiente; la indisciplina social y la carencia de adecuados sistemas de monitoreo ambiental.

También aparecen identificados los principales problemas relacionados con la eficiencia en el uso de los recursos y la sostenibilidad de la producción y el consumo nacional son el difícil acceso a las tecnologías de avanzadas; la insuficiente comprensión y aplicación del concepto de sostenibilidad; la atención dirigida a los procesos vinculados a la problemática ambiental de los productos y servicios; la poca aplicación de las herramientas de gestión por los empresarios y no ejecutar compras públicas sostenibles con un diseño sostenible y responsable extendido a todos los productores en las empresas en la forma de gestión estatal en su mayoría ante una apertura en la segunda década del siglo XXI de sujetos privados en el escenario mercantil que pueden competir con el sector estatal, sin tener en cuenta que lo verde vende en los mercados donde se pondera la etiqueta-certificación ambiental a los productos y al servicio que se prestan por los sujetos económicos.

Como colorario, el marco regulatorio complementario a la Ley No. 81 de 1997 por su vínculo con el control ambiental no garantiza la adopción de enfoques preventivos adecuados, aparejados a la indisciplina tecnológica que impera en la mayoría de las formas de gestión cubanas. A futuro, los costes en que incurrirá el Estado en la preservación del medio ambiente, tendrán importancia y una relevancia decisiva en los procesos futuros para la toma de las decisiones empresariales, de aquí que los procedimientos de la contabilidad de gestión ambiental sean de suma importancia para ejecutar la auditoría ambiental. Como evaluación ambiental y como valoración debe poseer un patrón contra el cual se efectuará la comparación y poder concluir sobre los sistemas examinados, de ahí que sean revisadas las anteriores revisiones realizadas a las entidades 
archivadas en el expediente contentivo de las acciones de control practicadas a través de la función inspectiva y la auditoría. En todo este patrón de comparación, variará de acuerdo al área sujeta al examen por parte del equipo auditor para realizarle la evaluación ambiental, requerirá que el equipo auditor tenga conocimientos sobre la estructura y el funcionamiento de la unidad económica sujeta a análisis, no sólo en su parte interna sino en el ambiente en la cual ella se desarrolla así como el cumplimiento de la normativa legal a la cual estará sujeta, deberá estudiarse el expediente legal de la organización auditada (Antúnez- Sánchez 2015e).

\section{FORMAS DE ACTIVIDAD ADMINISTRATIVA EN LA AUDITORÍA AMBIENTAL POR LAS EFS DENTRO DEL DERECHO PÚBLICO EN EL SECTOR ESTATAL CUBANO}

Las formas de actividad administrativa, que se adoptan en la ejecución de este tipo de auditoría a las formas de gestión privadas es realizada por auditores de sociedades mercantiles certificados por la EFS para ejercitar esta función pública en la nación, para ello necesitan la concesión administrativa y el título habilitante para ejecutar esta función pública, esta es solicitada de manera voluntaria por interés del empresario al órgano supremo de control, reconocido de esta manera en la doctrina constatada por este autor, al decir de autores como Jordana de Pozas (1942), Nieto (1976), Peña-Solís (2003) y Sánchez-Morón (2009). De esta manera, apreciamos como han incursionado en el control ambiental con la práctica de la auditoría, como proceso y procedimiento para proteger el medio ambiente, a partir del siglo XX, con tres tipos de auditorías al control del cambio climático, a la biodiversidad y al recurso hídrico, donde se pondera la evaluación de la juricidad.

Relacionado con la aseveración anterior, se considera a la concepción de servicio público, concepto controvertido, entendido de diversas formas y mutante en dependencia de las circunstancias políticas, económicas y sociales de los Estados, se ha construido sementada en los casos resueltos en un período en Francia desde el siglo XIX y XX. Actividad que progresa en el siglo $X X$ con el desarrollo de la Revolución Industrial, como consecuencia de los adelantos científico-técnicos acontecidos en esta época. Trajo como resultado la complejización de las relaciones sociales, donde la actividad industrial o de gestión económica quedó limitada a aquellas actividades de relevancia empresarial cuya titularidad se asumió por el poder público.

En la doctrina francesa, encontramos autores como Duguit (1925), Dromi (2000), Araujo-Suárez (2010) y Parejo-Alfonso (2011) con sus diferencias la consideran como la piedra angular del Derecho Administrativo clásico y para ello son argumentados elementos imprescindibles a la hora de determinarlo. A partir de las manifestaciones del servicio público, se identifican como elementos necesarios para su configuración: la necesidad de la sociedad o generalidad, la titularidad estatal, el régimen jurídico que permite que la Administración Pública gestione de manera directa o indirecta tanto el servicio como el control, la continuidad, uniformidad e igualdad de trato para todos los ciudadanos.

Es notoria que la intención del servicio público, es satisfacer las necesidades de la generalidad o colectividad, sin embargo, estas pueden ser en buena medida satisfechas a partir de servicios privados, es indispensable que el servicio que se realice tenga intrínseco la satisfacción del interés general. Sin olvidar que la consecución del interés público representa para la Administración Pública el fin de toda su actividad (Posada 1931).

Es así, que no sea necesario que el servicio público sea realizado por una entidad o agente público. En definitiva, no es el sujeto lo que califica la actividad sino el fin al que tanto se ha hecho alusión. Esta actividad puede ser realizada por sujetos que no son propios de la Administración Pública pudieran ser incluso particulares- o entidades con las mismas características que estos sujetos anteriormente descritos; sin que se pierda la titularidad. Como categoría jurídica, es concebida como forma de actividad estatal y de actividad técnica entre los mecanismos de control. Como categoría rectora del interés público, se percibe realizada y asegurada de manera continua, regular y uniforme, tutelada por la Administración Pública y gestionada de forma directa por esta o indirecta por sujetos autónomos autorizados, bajo un régimen jurídico especial, destinada a la satisfacción de un interés general, la protección del bien público ambiental al ser de uso colectivo. Se contempla además la forma de gestión mixta a través de sociedades mercantiles como ha sido ya citado, donde la Administración participa por sí o por medio de una entidad pública de conjunto con personas naturales o jurídicas en su acompañamiento al ejecutarla.

Autores como Lancís y Sánchez (1952), Parada (1997) y Matilla-Correa (2014) reconocen que hay características propias en el servicio público que lo distinguen del carácter 
de privado, pero esta diferencia es ocasional, ya que cambia de época en época y de un país a otro y que sobre el criterio que rige la calificación definitiva de un servicio como público o privado, no se ha dicho aún la última palabra.

Como actividad de control, es considerada como una de las actividades más importantes de la Administración Pública, sus destinatarios son las formas de gestión estatal y no estatal, sujetas a acciones de control administrativo por la norma legal que se establezca y están obligados a mantener sistemas de control interno, conforme a sus características, competencias y atribuciones institucionales, para fomentar empresas no contaminadoras al medio ambiente, denominadas a partir de la publicación de la ISO 26000 , como empresas amigables con el ambiente. Por lo que, su reconocimiento y regulación en los ordenamientos jurídicos contrastados, son corroborados como una prestación de servicio público, como actividad de control y de fomento al decir de Gordillo (2006). Para su ejecución, media la suscripción de un contrato de servicios, acción que concluye con la entrega del informe de los resultados de la auditoría practicada y la certificación ambiental (Antúnez- Sánchez 2014a).

En materia de protección, desde el Derecho Ambiental este tipo de control ha variado, a partir de la aplicación de otros mecanismos de control incorporados en el trascurso de los años, conocidos como técnicas de tutela ambiental a través del auto control, la fiscalización, la inspección, la auditoría, el ordenamiento ambiental, la información y la educación ambiental. Se aprecia que su aplicación pondera el principio de prevención, relacionada con otros principios del Derecho Ambiental, de la Contabilidad y de la Auditoría, al establecerse la aplicación de instrumentos de control como son: la autorización, la licencia y la concesión, evaluados a través de la auditoría ambiental, la policía ambiental y la supervisión ambiental, con el fin de mejorar la conciencia ambiental e identificar los riesgos, para concebir empresas amigables con el ambiente.

Como actividad de control, considerada como una de las actividades más importantes de la Administración Pública, sus destinatarios son las formas de gestión estatal sujetas a acciones de control que por la norma legal se establecen en sus ordenamientos jurídicos y que están obligadas a mantener sistemas de control interno conforme a sus características, competencias y atribuciones institucionales, como acción preventiva para proteger el ambiente. La finalidad, mantener, controlar y evaluar la efectividad del sistema en las instancias de dirección que le competen, considerado por autores entre los que se encuentran Dromi (2000), Gordillo (2006), y Muñoz-Machado (2011). Su importancia, se aprecia en la comprobación de las políticas del Estado en la preservación de las finanzas públicas y el control económico administrativo, donde se le ha incorporado la arista ambiental, que a criterio de este autor, evalúa la responsabilidad como otro de los principios del Derecho Ambiental vinculados a la práctica de la auditoría pública en materia ambiental (Antúnez- Sánchez 2015b).

Como actividad de gestión económica, se analiza el uso de los instrumentos económicos, considerados por la doctrina administrativa en materia ambiental como una alternativa para atenuar los efectos de la problemática ambiental, estos modifican las conductas de producción y de consumo al concebirlas como empresas sostenibles. Aparece entonces en este escenario, la alternativa jurídico-económica, con el uso e implementación del tributo ambiental, elemento utilizado para obtener un desarrollo limpio, en relación con el principio -de quien contamina paga- del Derecho Ambiental (Caferrata 2010). Por su vinculación con esta actividad de control ambiental practicada a las formas de gestión estatal y no estatal, en relación a la actividad que realicen, es implementada y controlada por el Fisco en normativas tributarias, vinculada al vertido ambiental generado en la producción, abren el camino al utilizar nuevos instrumentos de protección, con el impuesto ambiental, la promoción de I+D+I, y la certificación ambiental para conformar empresas amigables con el ambiente, que incluso pudiera también observar que la empresa los resultados de su producción o servicios hayan obtenido la etiqueta-certificación ambiental donde se pondere el marketing empresarial que tribute a una estrategia ética y sostenible (Antúnez-Sánchez 2015c).

Otra de las aristas vinculadas con el control ambiental, es apreciada a través del fomento ambiental, estímulo que promueve la Administración Pública para que las empresas sean menos contaminadoras, es regulado en normativas jurídicas a través de Leyes de Fomento en los ordenamientos jurídicos analizados. En los países de la región de Iberoamérica, se constata el reconocimiento de estos estímulos fiscales por la doctrina ambiental, a través de impuestos o reformas fiscales verdes, estos son utilizados como instrumentos de mercado, de aplicación al uso del transporte híbrido o eléctrico; en el reciclaje del plástico; en el control de la deforestación boscosa; en el tratamiento al 
agua potable y los desechos sólidos; en la conservación de la biodiversidad y en el uso de combustibles fósiles para modificar la matriz energética, se aprecia además su vinculación con la reingeniería de procesos en la industria a través de las tecnologías al final del tubo y con los encadenamientos productivos por su relación con la auditoría ambiental, señalado por Ríos-Gual (2007), SáezVaca (2009) y Ospina-Duque (2011).

La doctrina ambiental para la práctica de esta evaluación ambiental, se reconocen dos variables, una a través de la competitividad empresarial y otra en la protección ambiental con la entrega de instrumentos de acreditación ambiental al decir de Martín-Mateo (1994), Sanz-Rubials (2012) y MoraRuiz (2014), permiten distinguir el tránsito desde la actividad de limitación u ordenación -policía- hacia la de fomento en este siglo XXI, fortalecida con la aparición en todo este escenario de las normas EMAS y la ISO 26000.

Es por ello, que los conceptos, principios y elementos establecidos desde la doctrina ius administrativa relacionada con otras ramas del Derecho, en particular con el Derecho Ambiental, este autor analiza la relación que tienen con esta tipología de auditoría. Los ordenamientos jurídicos de Iberoamérica, la reconocen como una actividad de control y como servicio público, en sí conllevan acciones de control, permiten medir la eficacia y eficiencia de las actividades auditables ambientales en las formas de gestión no estatal, concebidas a través de la aplicación de las normas EMAS al aplicarse el autocontrol con una menor intervención pública en las industrias de forma obligatoria; toda vez que como gestión ambiental moderna, es transparente, participativa y concebida como un sistema de mercado para todos los países de la Unión Europea, al aportarles una gestión medio ambiental de calidad, de obediencia a la legislación ambiental, les permite la obtención de ayudas financieras, licencias y permisos ambientales, vinculadas a los principios del Derecho Ambiental que la informan, como el de responsabilidad, autocontrol, e información, para lograr la sostenibilidad ambiental.

Es así, que la actividad de control ambiental, tiene también vinculo en el desarrollo urbano, compatible con las políticas no contaminadoras, vinculadas en su ejecución a otros instrumentos de gestión ambiental, como la evaluación de impacto ambiental, la licencia ambiental y la inspección, con un fin, lograr el equilibrio con empresas ambientales responsables con la introducción y generalización de la norma ISO 26 000. En conjunto permiten el desarrollo adecuado del ordenamiento urbano sostenible con estrategias para mejorar la calidad ambiental y convertir las ciudades en lugares de vida, de trabajo e inversión atractivos y sanos, donde el impacto ambiental negativo sea mínimo. Para ello, son integradas las políticas urbanas con una gestión ambiental sostenible, mejor planificada, con un transporte urbano sostenible; permiten en conjunto minimizar los efectos adversos sobre los recursos naturales necesarios como el agua, el aire y la energía, al decir de autores como Pereira-Basanta (2011), González-Rodríguez (2011), Van Leeuwen (2013).

Hay también un reenfoque en su visión, al integrarse las necesidades colectivas y el entorno social, ello permite promover la educación ambiental, orientada a incrementar la cultura popular de los problemas ambientales que hoy afectan al planeta, donde los ciudadanos y la Administración Pública tienen una carga en la responsabilidad de obedecer las políticas públicas a partir del binomio deber-derecho, como lo señalan autores como Martín-Retortillo Báquer (2006), Villavella-Armengol (2011), y Zaffaroni (2012).

Es así, que la contaminación ambiental y los modelos urbanistas integrados, buscan la armonía social con un reenfoque del pensamiento ambiental, al ser la ciudad parte del paradigma ambientalista, al promoverse un urbanismo sostenible con nuevas estrategias ambientales urbanas por la Administración Pública, esta fomenta el transporte colectivo como nueva cultura, el respeto a los espacios peatonales, a las aceras y plazas como elementos integrales en la defensa ambiental, posiciones estas asumidas por Moreno-Viqueira (2009), Rueda (2009) Millán-Santana (2011), CampesinoFernández (2011) y Patiño-Posee (2012) por la importancia que tiene la aplicación de estas políticas por parte de la Administración Pública para proteger el ambiente.

\section{CONCLUSIONES}

La auditoría ambiental emergió debido a la contaminación empresarial y su enfrentamiento por el Estado, su génesis fue la auditoría social. Se consolida posteriormente como acción de control practicada por las Entidades Fiscalizadores Superiores y las Sociedades Mercantiles, posee una construcción jurídica a partir de estar reconocida en Convenios y Acuerdos Internacionales, es introducida en los derechos internos mediante los textos constitucionales, las leyes ambientales y de contralorías, brindan solidez y sustento para el desarrollo de políticas ambientales como la 
herramienta de gestión ambiental. Puede ser voluntaria u obligatoria y manifestarse como una actividad policía, un servicio público $\mathrm{u}$ actividad de fomento acorde a su ejecución y consecuencias.

La sistematización de la auditoría ambiental, como institución jurídica dirigida a proteger al bien jurídico ambiental, es reconocida desde la doctrina ius administrativa y la ius ambientalista. Los criterios teóricos y normativos valorados permitieron establecer que la realización de la auditoría entraña una relación jurídica ambiental y delimitar sus elementos: subjetivos (auditores y auditados), objetivos (contenido, instituciones y categorías a evaluar) y formales (documentos acreditativos de su validez).

La auditoría ambiental tiene un carácter multidimensional, integral y transdisciplinario, su finalidad es la evaluación de la gestión ambiental de la empresa y la certificación de producciones limpias, para realizarla las entidades auditadas deben implementar la contabilidad ambiental y el tratamiento de los residuales de la producción de la empresa. Constituye un proceso integrado por fases (preparación-ejecución-conclusión) cuyo procedimiento fundamental está regulado en al normas ISO y las EMAS.

La auditoría ambiental, en su ejecución se aprecia como una actividad de limitación u ordenación -policía-, practicada por las EFS con su encargo público, en atención al ordenamiento jurídico que la regule, es también ejecutada por Sociedades Mercantiles, reconocida con un -servicio público-, aporta luego de su conclusión valores agregados como la ética empresarial, la certificación contable, las producciones limpias, ética empresarial, competitividad empresarial y la certificación ambiental a las empresas amigables con el ambiente, permitiéndole el acceso a mercados más exigentes.

La auditoría ambiental, en la actualización del modelo económico cubano, deberá tener un valor importante, toda vez que permita transitar a las formas de gestión de la certificación de la calidad hacia la certificación ambiental, ello permitirá la competencia entre las empresas estatales y las no estatales en el mercado interno y en el foráneo como empresas amigables con el ambiente. Necesitada de su regulación en el ordenamiento jurídico del país para las formas de gestión no estatal.

\section{REFERENCIAS}

ANTÚNEZ-SÁNCHEZ, A. 2014a. Presupuestos jurídicos vinculados al control ecológico como actividad de los servicios públicos ambientales. Una mirada desde el sector empresarial estatal cubano. Revista de Derecho y Ciencias Sociales Misión Jurídica. 7. Colombia: 119-141pp.

ANTÚNEZ-SÁNCHEZ, A. 2014.b Disquisiciones teóricas, doctrinales y exegéticas sobre la praxis de la auditoria como función pública, dirigida a la protección del bien público ambiental para el empresa ecológica. Revista Actualidad Jurídica Ambiental. 40. España: 9-51pp.

ANTÚNEZ-SÁNCHEZ, A. 2015a. La auditoría ambiental, nexo con la empresa amigable del medio ambiente. Revista de Auditoría y Gestión de los Fondos Públicos. 65. España: 71-80pp.

ANTÚNEZ-SÁNCHEZ, A. 2015b. La auditoría ambiental y la industria amigable con el ambiente, meta del desarrollo sostenible en el Derecho Ambiental para Cuba por parte de la EFS-CGR. Revista Diálogos de Derecho y Política. 16. Colombia: 33-49pp.

ANTÚNEZ-SÁNCHEZ, A. 2015c. La auditoría ambiental, principios del Derecho Ambiental que la informan. Revista Monfrague Desarrollo Resiliente.2. España: 165-190pp.

ANTÚNEZ-SÁNCHEZ, A. 2015d. La auditoría ambiental: Una revisión y propuestas en clave de su función pública y dimensión empresarial. Revista Iberoamericana de Contabilidad de Gestión. 26. España: 3-27pp.

ANTÚNEZ-SÁNCHEZ, A. 2015e. La auditoría pública con enfoque ambiental y el tributo ambiental. Aplicación e implementación en Cuba. Revista Internacional Legis de Impuestos. Colombia.

ANTÚNEZ-SÁNCHEZ, A. 2015f. El tratamiento jurídico de la etiqueta-certificación ambiental. Regulación en el Derecho Cubano, Revista Iberoamericana de Derecho Ambiental y los Recursos Naturales. 18. Argentina.

ARAUjO-JUÁREZ, J. 2010. Derecho Administrativo General. Servicios Públicos. Ediciones Paredes. Caracas.

CAFERRATA, N. 2010. Principios del Derecho Ambiental.

Ediciones Abeledo Perrot S.A. Argentina. 
CAMPESINO-FERNÁNDEZ, A. 2011. Eurociudades y medio ambiente. Revista de Geografía. España: 1-36pp.

DUGUIT, L. 1925. Las transformaciones del Derecho Público, $3^{a}$ edición. Ediciones Colín. Francia.

DROMI, R. 2000. Derecho Administrativo. 8va edición. Ediciones Ciudad Argentina. Buenos Aires.

FERNÁNDEZ RAMOS, S. 2002. La actividad administrativa inspectora. El régimen jurídico general de la función inspectora. Ediciones Comares. Granada: 21-29pp.

GONZÁLEZ RODRÍGUEZ, C. 2011. Empresas socialmente responsables y mercado verde internacional. Revista Economía. 36. México D.F.

MARTÍN-RETORTILLO BÁQUER, L. 2006. Derechos fundamentales y medio ambiente. Ediciones Universidad Complutense de Madrid.

MARTÍN-MATEO, R. 1994. El etiquetado ecológico, nuevo instrumento para la tutela ambiental. Ediciones Trivium. España.

MARTÍN-MATEO, R. 1991. Tratado de Derecho Ambiental. Ediciones Trivium. España.

MARTÍN MATEO, R. 1993. La ecoauditoría. Boletín de Estudios Económicos. 150. España.

MATILLA-CORREA, A. 2014. Derecho Administrativo y servicio público. Trazos inconclusos desde una perspectiva histórica. Revista Jurídica. México: 383-444pp.

MUÑOZ-MACHADO, S. 2011. Tratado de Derecho Administrativo y Derecho Público en General. Ediciones Iustel. España.

MILLÁN-SANTANA, J. 2008. La auditoría como mecanismo de protección del derecho a una vivienda digna. Revista de Auditoría Pública. 46. España.

MORA-RUÍZ, M. 2012. La gestión ambiental compartida: función pública y mercado. Revista Catalana de Derecho Ambiental. 4. España.

MORENO-VIQUEIRA, G. 2009. El urbanismo como elemento clave en el nuevo paradigma ambiental. Revista
Umbral. Puerto Rico.

NIETO, A. 1976. Algunas precisiones sobre el concepto de policía. Revista de Administración Pública. 81. España.

OSPINA-DUQUE, R. 2011. La reingeniería de procesos: una herramienta gerencial para la innovación y mejora de la calidad en las organizaciones. Revista de Psicología y Administración de Empresas.España:91-100pp.

RÍOS-GUAL, J. 2007 La reingeniería aplicada al mundo empresarial del siglo XXI. Revista de Empresas. España: 110pp.

SANZ-RUBIALES, I. 2012. El mercado de los derechos a contaminar, Ediciones Lex Nova. España.

SANZ-LARRUGA, F. 2002. El principio de precaución en la jurisprudencia comunitaria. Revista Aranzadi de Derecho Ambiental.1. España: 117- 131pp.

SÁNCHEZ-MORÓN, M. 2010. Derecho Administrativo. 6 $6^{\text {ta }}$ edición. Ediciones Tecnos. España.

SÁEZ VACA, F. 2009. Reingeniería de procesos, características, principios y herramientas de aplicación. Revista de la Empresa. España.

JORDANA DE POZAS, L. 1942. Ensayo de una Teoría del Fomento en el Derecho Administrativo. Revista de Estudios Políticos. 5. España.

PAREJO-ALFONSO, L. 2000. El Estado social administrativo: algunas reflexiones sobre la crisis de las prestaciones y los servicios públicos. Revista de Administración Pública. 153. España.

PARADA, R. 1997. Derecho Administrativo. Tomo I. 9na edición. Ediciones Marcial Pons. España.

PATIÑO-POSSE, M. 2008. Tesis Doctoral: El régimen jurídico del ordenamiento ambiental y urbano. Universidad de Alicante. España.

POSADA, A. 1931. Tratado de Derecho Administrativo según las teorías filosóficas y la legislación positiva. Tomo I. Ediciones Madrid. España.

PEÑA SOLÍS, J. 2003. La actividad de la Administración Pública: 140 
Ambiente y Sostenibilidad 2015 (5):131-141

Revista del Doctorado Interinstitucional en Ciencias Ambientales

ISSN: 2339-3122

Digital

de policía administrativa, de servicio público, de fomento y de gestión económica. Manual de Derecho Administrativo. Volumen $3^{\text {ro }}$, Ediciones Colección de Estudios Jurídicos del Tribunal Supremo. Caracas. 107 y ss. pp.

PEREIRA-BASANTA, J. 2011. Tesis de Maestría: La autorización ambiental en el marco del procedimiento de evaluación de impacto ambiental: introducción a su régimen jurídico en Cuba, Universidad de La Habana.

LANCÍS Y SÁNCHEZ, A. 1952. Derecho Administrativo. 3ra edición. Ediciones Cultural S.A. La Habana.

LOZANO CUTANDA, B. 2015. Tratado de Derecho Ambiental. Ediciones CEF. España.

VAN LEEUWEN, S. 2013. El desarrollo de la auditoría ambiental dentro de la INTOSAI. Revista Internacional de Auditoría Gubernamental. 1. Estados Unidos de América.

VILLAVELLA-ARMENGOL， C. M. 2011. Los derechos humanos y el medio ambiente su tratamiento en el Derecho Constitucional comparado. Revista electrónica de Estudios Jurídicos. Cubalex, Unión Nacional de Juristas de Cuba. La Habana.

ZAFFARONI, E. R. 2012. La Pachamama y el humano. Ediciones Madres de la Plaza de Mayo. Buenos Aires. 